\title{
Dichotomy of principles and rules in R. Alexy's dual theory of law
}

\author{
Shakhboz Shavkatovich Sattorov ${ }^{1}$ \\ RUDN University, Department of Law and State Theory, Law Institute, Moscow, Russia
}

\begin{abstract}
The purpose of the study is a comparative legal analysis of approaches to principles and rules in R. Alexy's dual theory of law. The methodological basis of the study are the following fundamental methods of scientific knowledge: general methods (analysis, synthesis, induction, deduction, analogy), as well as special methods (comparative-legal and formal-legal). The application of these methods allowed to subject $\mathrm{R}$. Alexy's theory of law to an in-depth comparative legal study and to reveal the dichotomy of the principles and rules operating in it. The result of the study was the author's conclusion that weighing formal and material principles is not only possible, but also a necessary process. In addition, it should be mentioned that the dictate of optimization always requires the implementation of a weighing procedure, and that principles in theory are always implemented indirectly through rules. The principles themselves are the subject of optimization, and the dictate of optimization is the rule. Thus, principles are the basis of rules, and rules are the product of principles. The novelty of the study lies in the author's approach to the analysis of the dichotomy of principles and rules in the dual theory of law of R. Alexy, as well as the application of mathematical apparatus to substantiate the findings.
\end{abstract}

Keywords: principles of law, optimization thesis, weight formula, proportionality principle, human rights

\section{Introduction}

R. Alexy's theory of legal principles and his doctrine of the principles of law as dictates of optimization cause numerous discussions in modern legal theory, continuing the polemic of two antagonistic directions of legal thought, legal positivism and jusnaturalism. Adhering to the idea of opposing principles and rules following Dworkin, R. Alexy does not limit himself to attempting to justify the falsity of positivism's divisive thesis on the relation between law and morality, but takes the study of legal principles to a new theoretical level by developing a doctrine of human rights as principles of law whose application shall be limited by laws of optimization, collisionality and weighing. The proportionality test and R. Alexy's weighting formula allow to develop criteria for the permissibility of human rights restrictions, addressing the problem of the correlation between fundamental human rights and public interests and the competition of legal values in the law enforcement practice of

\footnotetext{
${ }^{1}$ Corresponding author: sattorov-shsh@rudn.ru
} 
the high courts. R. Alexy's weighting formula allows to apply the weighting procedure not only to determine priority relations between material principles that incorporate substantive values, but also allows to resolve conflicts between material and formal principles. To prove this idea, R. Alexy interprets Radbruch's formula on the relationship between the substantive principle of justice and the formal principle of legal certainty as the result of optimization and weighing. All of the above determines the importance and relevance of the topic of research, which allows to consider the problems of the relationship between law and morality, "legal non-law" and "supra-legal law", the limits of the interference of positive law in the sphere of natural and inalienable human rights and the criteria of admissibility of such interference, as well as the admissibility of the principles of law "contralegem" in terms of new approaches to the law.

R. Alexy's theory of legal principles is based on the doctrine of weighing, which is fundamental in his teachings on human rights and legal reasoning. According to R. Alexy, legal norms can be characterized by their structure within a strict dichotomy: a norm is either a principle or a rule [1]. The theoretical distinction between principles and rules is made on the basis of the degree of their obligation. Rules are a type of norms that dictate the final result, they are unconditional prescriptions, for this reason, knowledge of the legal rule provides recipients of legal rules sufficient grounds to determine their behavior as complying with the requirements of legal rules or as violating the prescriptions of the latter. In contrast to the rules, the duties imposed on the addressees of legal rules by the principles are applicable primafacie, that is, such duties and the degree of enforceability of the principles are subordinated to the factual and legal circumstances present in a particular case [2].

P. Alexy agrees with R. Dworkin that principles and rules differ in their logical nature. While rules are implemented on an all-or-nothing model and in a situation of mutual conflict can be either applicable, in which case they prescribe an end result, or inapplicable, in which case they will not affect the outcome of the case, principles have a different modality of obligation [3]. The principles have a measure of weight and can be implemented to a greater or lesser extent with regard to the actual and legal possibilities available, do not dictate with necessity the final result, and in a situation of conflict all competing principles are applicable. The rules are applied by subsumption and the principles require optimization.

\section{Methods}

To achieve the purpose of the study and to solve the tasks, the author used the following methods of scientific knowledge: general methods (analysis, synthesis, induction, deduction, analogy), as well as special methods (comparative legal and formal-legal). The application of these methods allowed to subject R. Alexy's theory of law to an in-depth comparative legal study and to reveal the dichotomy of the principles and rules operating in it.

\section{Results and discussion}

P. Alexy specifies 3 theses as the key principles for the theory he has developed.

\subsection{Optimization thesis}

From R. Alexy's perspective, "principles are norms that prescribe that something can be realized to a relatively high degree, based on actual and legal possibilities (circumstances)" 
[4]. Principles are dictates of optimization, and optimization is understood as a process aimed at the fullest possible realization of a certain value. With regard to the initial circumstances, different degrees of implementation of values (principles) can be optimal. When considering principles as dictates of optimization, then this recognition necessarily implies the possibility of varying degrees of implementation of the prescriptions of the principles, ranging from full compliance with the principle to complete disregard for what the principle requires. At the same time, rules operate on a different model, they are inherently binary, they may or may not be executed [5]. The fact that principles can be implemented to a greater or lesser degree does not mean that principles, as dictates of optimization, prescribe an arbitrary threshold for the implementation of the goal to be achieved. In fact, the principles prescribe the maximum possible (optimal) degree of implementation. The optimum is what is attainable under the circumstances, actual and legal. The legal circumstances (possibilities) are represented by the totality of other legal principles and rules applicable to the facts of the case, which are in conflict with the former [1]. In this regard, the dictates of optimization always require the implementation of a weighing procedure.

\subsection{The law of conflict nature}

As noted above, principles and rules differ in the nature of conflicts that arise between them and in the manner in which conflicts are resolved. Since the rules are binary, only one of them is applicable if there is a rule conflict. Conflicts between principles are resolved in a different way. As an example, R. Alexy refers to the decision of the Federal Constitutional Court of the Federal Republic of Germany, where it considered the issue of whether a person can participate in a trial depending on his/her state of health [6].

The law of conflict of laws shows that legal principles are not unconditional prescriptions, but contain a primafacie duty. Once the priority relations between the principles have been determined, the primafacie prescription contained in the principle with the greatest weight is transformed into a final prescription producing binding legal effects. P. Alexy formulates the conflict nature of laws as follows: "the conditions under which one principle takes precedence over another constitute the factual composition of the rule expressing the occurrence of the legal consequences prescribed by the more significant (weighty) principle. When designating the conflicting legal principles conditionally as $\mathrm{P}_{1}$ and $\mathrm{P}_{2}$, the existing circumstances of factual and legal nature in the case under consideration as $\mathrm{C}$, and the incoming legal consequences provided by the principle as $\mathrm{R}$, then the law of conflict of laws can be expressed by the following formula of R. Alexy:

$$
\left(\mathrm{P}_{1}>\mathrm{P}_{2}\right) \in \mathrm{C} ; \mathrm{C}->\mathrm{R} \text {. }
$$

It follows from this fact that principles are always realized indirectly through rules. The principles themselves are the subject of optimization, and the dictate of optimization is the rule. Thus, principles are the basis of rules, and rules are the product of principles.

The law of weighing.

The nature of principles as requirements of optimization implies a necessary connection between the theory of principles and the principle of proportionality. The principle of proportionality, which has recently gained great recognition in the practice and theory of constitutional control [7], consists of three sub-principles: the principle of suitability (admissibility), the principle of necessity, and the principle of proportionality in the strict sense of the word. All three sub-principles express the idea of optimization. For this reason, the theory of legal principles is implicitly inherent in the principle of proportionality and vice versa. The principles of suitability and necessity determine the precepts of optimization in relation to the actual circumstances. Optimization relative to actual possibilities is to avoid unnecessary costs. However, costs are inevitable when principles 
collide [8]. Then there is the need for weighing. Weighing is subject to the third sub-principle of the principle of proportionality, called the principle of proportionality in the strict sense. This principle defines what the prescription of optimization requires with respect to legal options.

To explain his concept of the principles and elements of the principle of proportionality, R. Alexy turns to concrete examples. Suppose that in order to protect the rights of consumers $\left(\mathrm{P}_{2}\right)$ some measure $\mathrm{M}$ is introduced, which is an interference with the principle of entrepreneurial freedom $\left(\mathrm{P}_{1}\right)$. In this case, the introduced measure $\mathrm{M}$ is not fully justified and appropriate, as such a measure generates unnecessary costs due to the fact that the absence of such a measure will not negatively affect the rights of consumers. The optimization of colliding principles requires the elimination of excess costs, i.e., it prescribes the rejection of the introduction of measure $M$. This constitutes the content of the sub-principle of suitability (admissibility) of the broader principle of proportionality in R. Alexy's theory of principles.

The sub-principle of necessity suggests that if there are two or more measures equally suited to the principle that carries greater weight under existing factual and legal possibilities, the measure that limits the effect of the conflicting principle to a lesser degree should be chosen. P. Alexy develops his example about the conflicting principles of consumer protection and freedom of enterprise. Suppose there are measures $M_{1}$ and $M_{2}$ that are equally suitable for implementing the principle of consumer protection. But the introduction of measure $\mathrm{M}_{2}$ would be less restrictive on the conflicting principle of entrepreneurial freedom. The principle of necessity dictates that measure $\mathrm{M}_{1}$ should not be imposed in such a situation.

The sub-principles of admissibility and necessity contribute to the prescription of the fullest possible realization of the legal principle regarding actual possibilities (circumstances). The sub-principle of proportionality in the strict sense of the word aims to achieve an optimizing dictum with respect to legal options. According to R. Alexy, in order to implement such a dictum, a weighing procedure is necessary, because in a situation of conflict of legal principles, the implementation of one principle always inevitably leads to the derogation of another principle. From R. Alexy's point of view, the sub-principle of proportionality in the strict sense can be summarized as follows: "the greater the degree of non-performance or infringement of one principle, the greater the importance of the implementation of the other principle" [9].

Thus, R. Alexy believes that principles are requirements of optimization, hence principles contain a primafacie prescription that can be implemented to a greater or lesser extent, with regard to existing factual and legal possibilities. In view of the fact that the conflict resolution pattern characteristic of principles always involves the realization of one principle at the expense of another at the simultaneous applicability of all the principles in question, the realization of principles always necessarily requires an analysis of the proportionality principle to determine the proportionate limitation of some principles for the sake of satisfying the values incorporated in other principles that carry the greatest weight.

Similar elements in the content of the principle of proportionality are highlighted by $\mathrm{S}$. Tsakirakis $[10,11]$. Thus, he argues that the principle of proportionality is a three-point test used in evaluation of:

a) whether a measure that imposes a restriction on human rights is appropriate to achieve a particular goal;

b) whether it is necessary for this purpose;

c) does not it unduly burden a person compared to the benefits it is meant to provide [12].

But R. Alexy goes even further in solving the problem of the contradiction of legal principles and determining the degree of limitation of one principle by another by 
developing a "weight formula". P. Alexy draws attention to the fact that in almost all national legal systems of constitutional justice one can find different ways of using the weight formula. The weight formula expresses the essence of the procedure of weighing colliding principles and is of great practical importance. P. Alexy expresses the weight formula he developed through the following external notation [13]:

$$
G_{a, b}=\frac{W_{a} \times P_{a} \times I_{a}}{W_{b} \times P_{b} \times I_{b}}=\frac{G_{a}}{G_{b}} .
$$

In this formula, the variable $a$ represents the interest pursued for the sake of which another conflicting principle is violated, the goal for the achievement of which the conflicting principle is restricted, while through $b$ we express the interest burdened by the violation, the interest to be restricted/modified in order to achieve a greater interest. $G_{a, b}$ denotes the specific weight of the principle $\mathrm{P}_{\mathrm{a}}$ in relation to the colliding principle $\mathrm{P}_{\mathrm{b}}$, which is calculated by the product of $\mathrm{W}$ (the value of the interest, the significance/importance of the satisfaction of the interest expressed by the principle), P (the probability of violation, limitation/impairment) and I (the intensity/extent of violation). At the same time, there are rules in the formula that determine the degree of deviation from the optimum:

(1) Disproportionate if: $G_{a, b}<1$ (i.e., $G_{b}>G_{a}$ );

(2) Proportional if: $\mathrm{G}_{\mathrm{a}, \mathrm{b}} \geq 1$ (i.e., $\mathrm{G}_{\mathrm{b}} \leq \mathrm{G}_{\mathrm{a}}$ ).

Thus, according to the weight formula, in a situation of conflict between two legal principles, it is always necessary to use the principle of proportionality to determine the relationship of priority between the conflicting principles and the degree of restriction/elimination of one principle for the sake of achieving the interest expressed by the more weighty principle.

\subsection{Formal and material principles}

P. Alexy distinguishes between formal and material principles. Since all principles are dictates of optimization, formal principles fall as much under the notion of dictates of optimization as rules which require that something be realized to the greatest extent possible on the basis of existing factual and legal possibilities. The distinction between formal and material principles is limited to what is addressed by the requirement to realize some interest, i.e., the object of optimization. Differentiaspecifica of material principles is that the objects of their optimization are represented by phenomena that have certain content, such as life, freedom of speech, a living wage, environmental protection, etc. On the contrary, the objects of optimization of formal principles are legal decisions and actions without regard to their content. Formal principles prescribe that the authority of norms made positive in a proper way and socially effective be optimized. The authoritativeness of the establishment and the social efficacy of the norm are the defining components of legal positivism [14]. From this, it follows that formal principles refer to the factual or empirical dimension of law.

P. Alexy believes that formal principles can be weighed and their weight can be determined in relation to material principles, as well as vice versa. He draws attention to the fact that there are many court cases in which formal principles have been and even should have been optimized in a situation where they conflict with substantive principles. As R. Alexy notes, after the collapse of National Socialism in Germany in 1945, just as after the fall of the GDR in 1989, German courts were confronted with a large number of cases raising the question of the unjust content of laws and determining the extent to which unequivocally unjust injunctions were binding. As a result, the courts have applied Radbruch's formula: "extreme injustice is not law" [15]. 
Indeed, the idea of law in the concept of G. Radbruch confirms the possibility of a conflict of formal and material principles. According to G. Radbruch, the basic elements of the idea of law are justice, expediency and stability [16]. Justice is a substantive principle in contrast to stability, which is identified with the positivist principle of legal certainty. The principle of fairness dictates that positive regulation shall be fair in its content. The principle of stability (legal certainty) prescribes strict compliance with positive normative prescriptions by all subjects of legal communication, because otherwise it is impossible to achieve the rule of law and a state of stability and settlement of rights and obligations. But G. Radbruch noted that in certain situations there may be a conflict between the individual elements of the law. P. Alexy truely refers to Radbruch's formula, stressing that the formula itself is the result of the weighing (optimization) of the substantive principle of justice against the formal principle of legal certainty. Achieving a balance between the principles rests on two laws. The first law was expressed in the weight formula discussed in this section. The second law is the law of competing principles, which establishes that, according to the weight of the competing principle $\mathrm{P}_{\mathrm{a}}$ established by the weight formula $\left(\mathrm{W}_{\mathrm{a}, \mathrm{b}}\right)$, a particular priority relationship shall be established with regard to the conditions (actual and legal) of the case. Radbruch's formula distinguishes between two conditions for determining the priority relations of principles. First, circumstances $\mathrm{C}_{1}$, which constitute a state of injustice below the threshold of extreme injustice. Second, a set of circumstances $\mathrm{C}_{2}$ that characterize extreme injustice. Under $\mathrm{C}_{1}$ circumstances, the formal principle of legal certainty takes precedence over the substantive principle of equity, but under circumstances below the threshold of extreme injustice, the substantive principle of equity should take precedence over the formal principle of legal certainty. According to the law of conflict nature, the effect of overriding the principle of legal certainty by the principle of equity is that the direction contained in the substantive principle of equity shall be implemented, which is what the Radbruch formula requires.

\section{Conclusion}

Thus, as can be seen in the discussion, the state of extreme injustice of positive legal regulation occurs only in extreme situations, it does not affect all legal norms of the legal system, but only those that involve a gross violation of justice. All this allows concluding that the weighing of formal and material principles is not only possible but also a necessary process.

\section{References}

1. R. Alexy, A Theory of Constitutional Rights (Oxford University Press, 2010)

2. R. Ramião, Some Fundamental Problems Concerning Alexy's Notion of Legal Principles, in D. Duarte, S.J. Sampaio (eds.), Proportionality in Law (Springer, 2018). https://doi.org/10.1007/978-3-319-89647-2_8

3. V.V. Lapaeva, R. Proc. Instit. State and Law Rus. Acad. Sci. 4, 142-169 (2013)

4. R. Alexy, Rus. Just. 3(131), 19-34 (2017)

5. N. Petersen, German Law J. 21(2), 163-173 (2020). https://doi.org/10.1017/glj.2020.9

6. H.S. Garcia, D.S.S. Garcia, Curitiba, 2(2), 147-168 (2016). https://doi.org/10.21902/Organização Comitê Científico Double Blind Reviewpelo SEER/OJSRecebido em:06/07/2016Aprovado em:12/12/2016

7. A. Barak, Proportionality, Constitutional Rights and their Limitation (Cambridge, 2012) 
8. R. Alexy, Chinese Y.B. Const. L. 221, 222-224 (2010)

9. R. Alexy, Int J Semiot Law 33, 35-46 (2020). https://doi.org/10.1007/s11196-019-09661-0

10. S. Tsakirakis, Comp. Const. Rev. 2(81), 47-66 (2011)

11. B. Schlink, Comp. Const. Rev. 2(87), 56-76 (2012)

12. I.A. Karaseva, Comp. Const. Rev. 4, 75-85 (2014)

13. R. Alexy, The Weight Formula, in J. Stelmach, B. Brożek, W. Załuski (eds.), Studies in the Philosophy of Law: Frontiers of the Economic Analysis of Law (Cambridge, 2007)

14. R. Alexy, The Argument from Injustice. A Reply to Legal Positivism (Clarendon Press, Oxford, 2002)

15. R. Alexy, A Defence of Radbruch's Formula (Faculty of Law, University of Toronto, 2000)

16. Sh.Sh. Sattorov, D.A. Korenkova, Edu. Law 1, 78-81 (2019) 